\title{
Evaluation of new polysaccharides networks for extended-release purposes: mesquite seed gum (MSG), xanthan gum and chitosan
}

\author{
Carlos César dos Santos Nogueira, Lúcio Mendes Cabral ${ }^{1 *}$, Tereza Cristina dos Santos², \\ Antonio Marucci $^{3}$, Franco Alhaique ${ }^{3}$
}

${ }^{1}$ Faculdade de Farmácia, Universidade Federal do Rio de Janeiro, ${ }^{2}$ Instituto Nacional de Controle de Qualidade em Saúde - Fundação e Instituto Osvaldo Cruz, ${ }^{3}$ Departamento di Studi di Chimica e Tecnologia delle Sostanze

Biologicamente Attive, Universita La Sapenza

*Correspondência:

L. M. Cabral

Faculdade de Farmácia

Universidade Federal do Rio de

Janeiro

Centro de Ciências da Saúde

Bloco K - Sala 050

21941-590 - Rio de Janeiro

Brasil

E-mail: Imcabral@pharma.ufrj.br
The aim of this work was to design new hydrophilic matrix (HM) systems by cross-linking Mesquite Seed Gum (MSG), a galactomannan that occurs in the endosperm layer of the seeds of a Brazilian tree, Prosopis juliflora DC, with two well-known polysaccharides with the ability of retarding drug release, chitosan and xanthan gum. This had in mind the idea of using these new compounds in the preparation of extended-release dosage oral forms. The first part of this study was dedicated to the evaluation of MSG in terms of its functionality as a hydrophilic matrix (HM) system for extended-release purposes. Next, we started the study of water uptake profile of all polymers of interest (MSG, Xanthan Gum and Chitosan), in the following media: water, SGF and SIF. Following, we searched for the best cross-linking agent between Glutharaldehyde (GA) and Hexamethylenediisocyanate (HMDI), which turned out to be the GA. Next step we begun to prepare new hydrophilic matrices of MSG_Chitosan and MSG_Xanthan Gum, with different ratios, 1:1, 1:2 and 2:1. Finally, after deciding which new HM system presented best results, by using statistics tools, we investigated the mechanism controlling the rate release of the model drug, from tablets made with this new matrix. As a final result we concluded that the best combination of polysaccharides was achieved with MSG and Xanthan Gum, with mass ratio of 1:2, using glutharaldehyde aqueous solution as cross-linking agent. It presented a prevalent zero order kinetics, which is a very important feature when thinking about an extended-release oral dosage form.
Unitermos:

- Mesquite seed gum (MSG)

- Chitosan

- Xanthan gum (XG)

- Hydrophilic matrix (HM)

- Cross-linking reactions

- Extended-release oral dosage forms

\section{INTRODUCTION}

The advantages of administering a single dose of a specific drug that is released over an extended period of time, instead of several doses, are well known to meet the pharmaceutical industry and medicinal purposes. Various drug delivery technologies have been developed to extended-release objectives, including layered tablets, osmotic pumps and use of hydrophilic matrices (HM). Since their introduction, HM systems have been of great 
industrial interest due to their simple manufacture to manufacture, low costs and good biocompatibility. Several different hydrocolloids are often used in extended-release formulations, such as cellulose ethers (Lapidus, Lordi, 1968), chitosan (Acartürk, 1989) scleroglucan (Alhaique et al., 1989) guar gum (Syed et al., 1998) and MSG (Cavalcanti et al., 1998). However, the major disadvantage of this type of system is that usually it does not follow a Fickian drug diffusion mechanism, producing different release profiles (Lee, 1985), showing at the same time results with low reproducibility (Felt et al., 1999). Among the various approaches to achieving zero order release of drugs, the change of cross-linking density of the polymer (Reinhart et al., 1981) and the use of swelling-controlled delivery systems were investigated (Lee, 1984; Shah et al., 1991). Another very useful tool was the preparation of new hydrophilic matrices by cross-linking (Coviello et al., 1998) different polysaccharides in order to modulate the characteristics of these new polymers for extended-release purposes. The aim of this work is to investigate the drug release mechanism of a galactomannan obtained from the seeds of Prosopis juliflora (Mesquite Seed Gum - MSG) and its use in the preparation of new hydrogels by crosslinking it with other polysaccharides - chitosan and xanthan gum - in order to optimize its extended-release behavior and drug release kinetics.

\section{MATERIALS AND METHODS}

\section{Materials}

Theophylline (TPH), propranolol.HCl (PROP), indomethacin (IND), salicylic acid (SA), sodium salicilate (SS) were USP XXIV. Lactose (Carlo Erba-Italy), rice starch (Chimisan-Italy), pregelatinized starch (Laingnational-UK), microcrystalline cellulose, polyvinyl pyrrolidone (PVP K-30), chitosan (medium and high molecular weight Mr. $=400.000$ and 600.000), xanthan gum $\left(\mathrm{Mr}=2.0 \times 10^{6}\right)$ (Fluka Chemica-Switzerland), glutharadehyde (GA) (Acros Chem.-U.S.A.) and hexamethylenediisocyanate (HMDI) (Aldrich Chem. U.S.A.) were used as supplied.

In all preparations of solutions and buffers, distilled water was used. SGF and SIF (Simulated gastric fluid and Simulated intestinal fluid) were prepared as indicated by USP XXIII. Coarse Mesquite Seed Gum was purified to appropriate form by filtration and obtained in the (40 mesh) by spray-drying (Büchi Mini Spray Drier B191); inlet air temp. $184-185^{\circ} \mathrm{C}$, outlets air temp. $120-121^{\circ} \mathrm{C}$, flow rate $0.6 \mathrm{~L} / \mathrm{h}$; the pump was set at a value of 20 and the overall yield was $71 \%$. The purified product showed a viscosity of $3300 \mathrm{cps}\left(1 \%(\mathrm{w} / \mathrm{v})\right.$ aqueous solution $25^{\circ} \mathrm{C}$ at $20 \mathrm{rpm}$, RVT Brookfield viscometer), a moisture content of $12.5 \%$ and average molecular weight of 2.0-3.0 x $10^{6}$. In this study MSG was extracted from the seeds collected in January, March and December 1997.

\section{Tablets preparation}

Tablets weighing $250 \mathrm{mg}$ (diameter $12.00 \mathrm{~mm}$ and thickness $1.35 \mathrm{~mm}$ ) were prepared by wet granulation with ethanol: water $(1: 1)$ mixture or another suitable binder solution from a mixture $(5: 3: 2)$ of polymer-drugexcipient. The granulating compression was done in a Perkin-Elmer hydraulic press at a pressure equivalent to 5 $\mathrm{KN}$ for $5.0 \mathrm{~min}$. The use of matrix solutions as binder or tablets components solubilisation and liophylisation was avoided to obtain more realistic conditions regarding the extended-release tablets in industrial production. A PVP $\mathrm{K}-305 \% \mathrm{w} / \mathrm{v}$ aqueous solution was used as binder and lactose, rice starch and microcrystalline cellulose used as filler, intragranuraly incorporated. The hardness of the tablets obtained was measured with a Monsanto hardness tester apparatus, and the value observed ranged from 6.5 to $7.0 \mathrm{~kg}$ /force. The weight obtained in all tablets ranged from 250 to $252 \mathrm{mg}$.

\section{In vitro drug release studies}

The dissolution experiments were carried out according to the USP XXIII apparatus I (basket) at $37{ }^{\circ} \mathrm{C}$ using $900 \mathrm{~mL}$ of dissolution medium. At fixed time intervals, $5.0-\mathrm{mL}$ samples were collected and spectrophotometrically assayed, after dilution, with a Perkin-Elmer Series $634 \mathrm{UV}-\mathrm{Vis}$ spectrophotometer at the appropriate wavelength. The influence of surfactants on drug release was also evaluated by adding Tween $801.0 \%$ (w/v) to the dissolution medium. The release rate experiments were carried out in triplicate.

\section{Data analysis}

The data obtained were plotted according to the following equations that describe different release kinetics of the drug from matrices:

Zero order: $\% \mathrm{D}=\mathrm{a}_{1}+\mathrm{b}_{1} \cdot \mathrm{t}$ (equation 1 )

First Order: $\ln (100-\% D)=a_{2}-b_{2} \cdot t$ (equation 2)

Higuchi: $\% \mathrm{D}=\mathrm{a}_{3}+\mathrm{b}_{3} \cdot \mathrm{t}^{1 / 2}$ (equation 3 )

RRSBW distribution: $\ln [100 /(100-\% \mathrm{D})]=\mathrm{a}_{4}+\mathrm{b}_{4} \ln \mathrm{t}$ (equation 4)

where $\% \mathrm{D}$ is the percentage of drug released, $\mathrm{t}$ is the time and $\mathrm{a}_{1}, \mathrm{a}_{2}, \mathrm{a}_{3}, \mathrm{a}_{4} ; \mathrm{b}_{1}, \mathrm{~b}_{2}, \mathrm{~b}_{3}, \mathrm{~b}_{4}$ represent the intercepts and 
the slopes respectively. One way ANOVA was used to evaluate the influence of different parameters on the release of the drug from the matrix.

\section{Dynamic Swelling Studies}

The dynamic swelling behavior of the polymers in aqueous media of varying $\mathrm{pH}$ at room temperature was studied. The dry polymer tablet $(150 \mathrm{mg})$ was weighted and immersed in the aqueous medium. After $20 \mathrm{~min}$. the tablet was removed, blotted with tissue paper and weighed on a Mettler analytical balance. This procedure was repeated every 20-min. until $120 \mathrm{~min}$, when no further weight gain was observed. In all cases equilibrium swelling was calculated from the equation:

Equation 5: \% Swelling $=\frac{\left(\mathrm{W}-\mathrm{W}_{\mathrm{o}}\right)}{\mathrm{W}_{\mathrm{o}}} \times 100$

where $\mathrm{W}$ denotes the weight of the swollen tablet and $\mathrm{W}_{\mathrm{o}}$ denotes the weight of the dry tablet.

\section{Erosion studies}

The method used for the evaluation of erosion of tablets containing theophylline, lactose and polymers was very similar to that used in the dissolution studies. In this experiment, the tablets were placed in the clean baskets and then weighed accurately. The dissolution process was carried out for $120 \mathrm{~min}$ at $150 \mathrm{rpm}$ in SGF - $37^{\circ} \mathrm{C}$ and the basket containing the remains of the tablet was removed and dried at $50^{\circ} \mathrm{C}$ for $24 \mathrm{~h}$. After cooling in a dissector to room temperature, the residues were weighed accurately and the loss, in percentage, was calculated considering the drug release ( $\%$ of theophylline release).

\section{Preparation of cross-linked polysaccharides}

\section{Glutharadehyde cross-linking reactions}

In separate experiments, $1.0 \mathrm{~g}$ of MSG and chitosan were dissolved for $1.0 \mathrm{~h}$, at room temperature in $150 \mathrm{~mL}$ of distillated water and acetic acid solution $1.0 \%(\mathrm{v} / \mathrm{v})$ respectively. Then concentrated $\mathrm{HCl}(0.5 \mathrm{~mL})$ was added, in both cases followed by the addition of 5.0, 10.0, 15.0, 20.0 and $40.0 \%(\mathrm{v} / \mathrm{w})$ (in relation to total polymer weight) of glutharaldehyde. The reaction mixture was stirred for $48 \mathrm{~h}$ at room temperature. The resulting viscous solution was reacted with a $5.0 \% \mathrm{w} / \mathrm{v}$ aqueous solution of $\mathrm{NaHSO}_{3}$ for 2 hours, precipitated with ethanol and the resulting product rinsed three times with an Ethanol: $\mathrm{H}_{2} \mathrm{O}$ 70:30 mixture. The cross-linked products were lyophilized to give $850 \mathrm{mg}$ of dry powder of each product.

\section{HMDI cross-linking reactions}

In separate experiments, $1.0 \mathrm{~g}$ of MSG or chitosan was dissolved for $1.0 \mathrm{~h}$, at room temperature, in $150 \mathrm{~mL}$ of distillated water or acetic acid solution $1.0 \%(\mathrm{w} / \mathrm{v})$ respectively. Followed by the addition of 5.0, 10.0, 15.0, 20.0 and $40.0 \%(\mathrm{v} / \mathrm{w})$ of HMDI in each flask. The reaction mixture was stirred for $48 \mathrm{~h}$ at room temperature. To the resulting viscous solution was added with $1.0 \mathrm{~mL}$ of concentrated sulfuric acid and stirring for $2 \mathrm{~h}$. This solution was mixed with ethanol and the product was washed three times with an ethanol: $\mathrm{H}_{2} \mathrm{O}$ 70:30 mixture. The crosslinked products were lyophilized to give $800 \mathrm{mg}$ of dry powder of each product.

\section{Synthesis of cross-linked compounds}

The compatibility of the components of the new matrices was evaluated by infrared spectroscopy in the physical mixture prepared under the same experimental conditions adopted in the synthesis of all other crosslinked polysaccharides, without the use of cross-linking agents. These products were prepared starting from $1.0 \mathrm{~g}$ of the polysaccharide mixture (weight ratio 1:1, 1:2 and 2:1) dissolved in $200 \mathrm{~mL}$ of distilled water (MSG_Xanthan Gum reactions) or $1.0 \%(\mathrm{v} / \mathrm{v})$ acetic acid aqueous solution/water (1:1) mixture (MSG_Chitosan reactions) until the disappearance of all material in suspension. After filtration of the yielded solution, an appropriate amount of glutharadehyde was added and the reaction medium was stirred for $48 \mathrm{~h}$ at room temperature. The viscous solution obtained was reacted with a $5.0 \%$ (w/ v) aqueous solution of $\mathrm{NaHSO}_{3}$ for $2 \mathrm{~h}$, and the yielded products were freeze-dried after exhaustive dialysis, with distilled water. The cross-linking reactions were done in triplicate. All products obtained were characterized by infrared spectroscopy (Perkin-Elmer FTIR spectrometer Paragon 1000). The differential scanning calorimetry (DSC) measurements were obtained in a Perkin Elmer DSC 7 apparatus.

\section{RESULTS AND DISCUSSION}

\section{Evaluation of the influence of excipients in MSG tablets drug rate release}

In previous studies Cavalcanti et al. (1998), described the successful use of MSG as a Hydrophilic Matrix System, reporting good results with insoluble and soluble lipophilic drugs were used as model drug. 
However, a considerable burst effect was observed with hydrophilic model drugs, indicating a probable polymer erosion contribution to the drug release control mechanisms. The data fit better into a RRSBW kinetics model. Three lots of each proposed formulations (Table I) were prepared using theophylline as model drug in view and wanting to elucidate the excipients variations influences of MSG as hydrophilic matrix system. As one can observe in Figure 1, the best extended-release behavior was obtained when pregelatinized starch was used as filler, followed by the tablets prepared with microcrystalline cellulose $(\mathrm{p}=0.0013)$. Considering that pregelatinized starch and lactose are soluble in water, which does not apply to microcrystalline cellulose (Daskolakis, 1994), it was possible to correlate the improvement of matrix efficiency with the increase in compaction, and not with the reduction in the solubility of the excipient. The tablets prepared without filler (formulation D) showed a higher theophylline amount of release, confirming the close relation between granulation compactability and drug retarding ability (Cavalcanti, 1998; Carstensen, 1987). A zero order drug release kinetics was observed with all excipients used in SGF, the best correlation being obtained from the tablets prepared with pregelatinized starch as filler $(r=0.9942)$.

\section{Evaluation of the influence of crop to crop variations on extended-release profile of MSG tablets}

Formulations containing lactose as filler, was prepared with MSG extracted from seeds collected in December 1997, January and March 1998, in order to
TABLE I - Composition of MSG tablet formulations

\begin{tabular}{lcccc}
\hline Ingredients (\%) & \multicolumn{4}{c}{ Formulations } \\
& A & B & C & D \\
\hline MSG & 50 & 50 & 50 & 50 \\
Lactose & 30 & - & - & - \\
Pregelatinized starch & - & 30 & - & - \\
Microcrystalline cellulose & $\overline{20}$ & $\overline{20}$ & 20 & - \\
TPH & 20 \\
\hline
\end{tabular}

evaluate a possible influence of crop to crop variations in the MSG extended-release profile. In all formulations, the initial original characteristics of the material such as particle size distribution, viscosity, water content, were kept constant as granulation parameters and compaction force applied in compression process. No variations from crop to crop effects were observed in the extended-release profile of the samples tested (Figure 2).

\section{Investigation of drug release mechanism from MSG matrix}

For an appropriate evaluation of the drug delivery control mechanism observed for MSG matrix, the propranolol. $\mathrm{HCl}$ (lipophilic drug) and theophylline drug release profile was evaluated using MSG tablets containing different amounts of these drugs, with drug release rate expressed as a function of the square root of time (Table II). A linear trend was obtained in all the cases studied, the major correlation coefficient being observed with the tablets with a reduced drug loading.

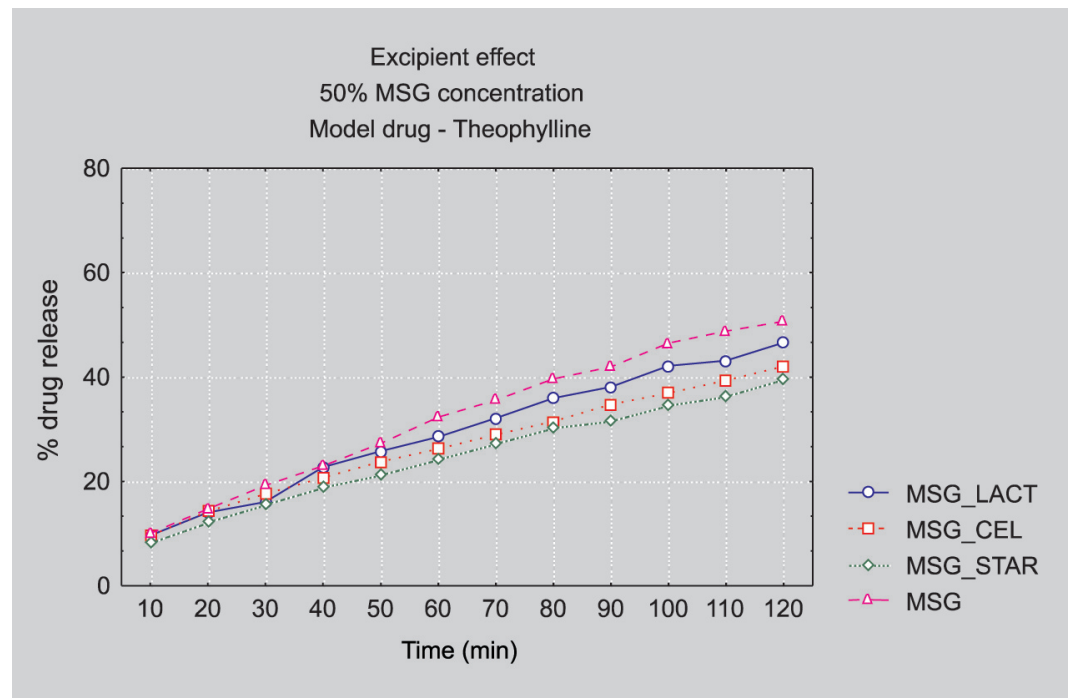

FIGURE 1 - Evaluation of excipient modification influence in extended-release profile of MSG tablets, in SGF. 


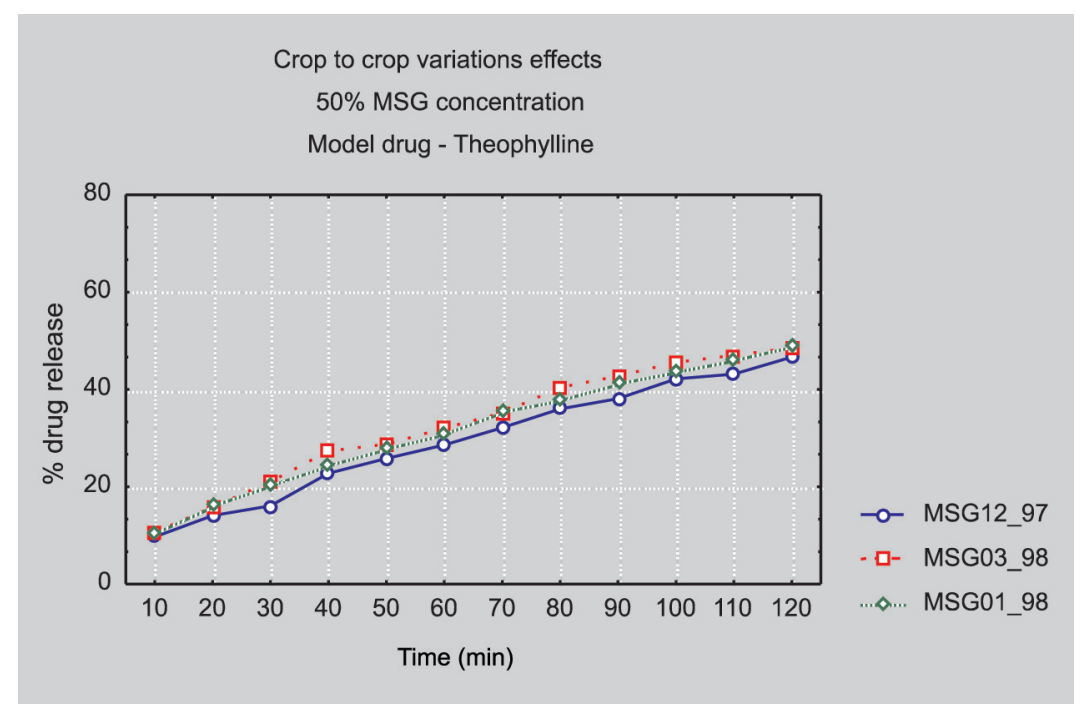

FIGURE 2 - Evaluation of crop to crop variation influence in extended-release profile of MSG tablets, in SGF.

TABLE II - Plot of drug release amount vs. square root of time from MSG matrix tablets

\begin{tabular}{lcc}
\hline Model Drug & $\begin{array}{c}\text { Drug Content } \\
(\mathbf{m g})\end{array}$ & $\begin{array}{c}\text { Correlation } \\
\text { Coefficient (r) }\end{array}$ \\
\hline Theophylline & 50 & 0.9956 \\
Theophylline & 15 & 0.9985 \\
Propranolol.HCl & 50 & 0.9912 \\
Propranolol.HCl & 15 & 0.9985 \\
\hline
\end{tabular}

These results suggest that the drug delivery and rate control mechanism are related to the diffusion of model drug through the gel layer.

In order to confirm the controlled diffusion hypothesis, another drug release experiment was carried out using model drugs that show solubility dependent on $\mathrm{pH}$ (salicylic acid/sodium salicylate). The results using SGF as dissolution medium, reported as function of time, did not show significant differences in the dissolution profiles of each one from the model drugs $(\mathrm{p}=0.8615)$. Thus, it was possible to conclude that the mechanism and rate control of drug delivery from this matrix were related to the drug diffusion through the gel layer (Figure 3).

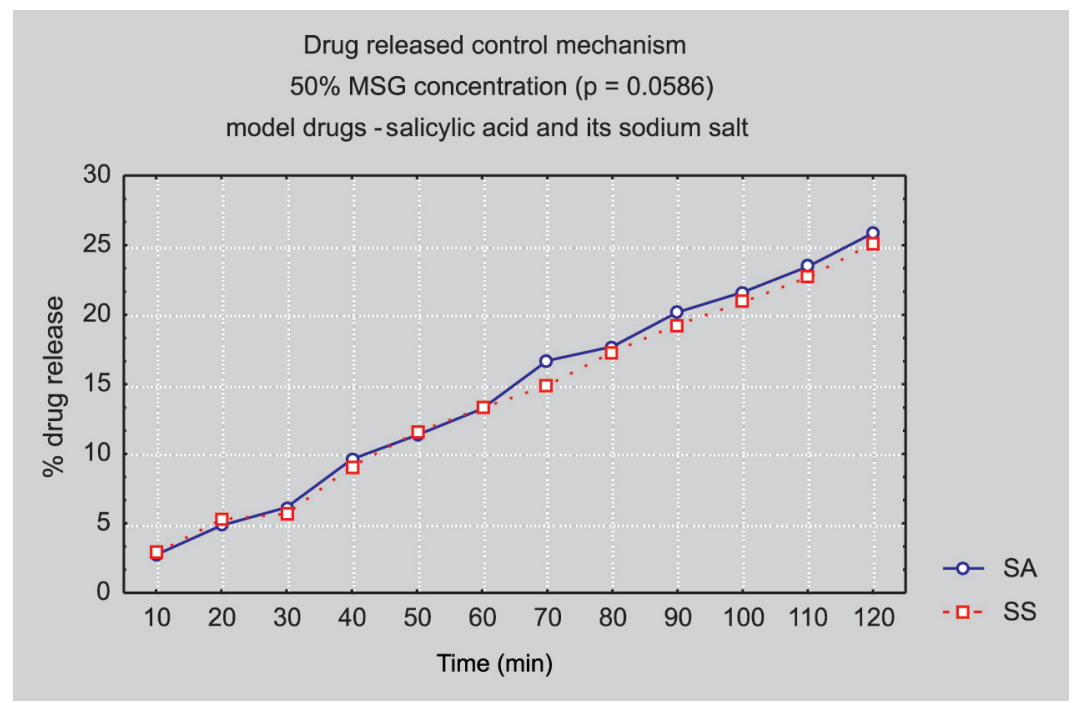

FIGURE 3 - Investigation of drug release control mechanism from MSG matrix. 


\section{Investigation of the effect of addition of surfactant and decrease in drug load on drug release profile}

In order to exclude any possible influence of the velocity solvent penetration and wetting influences on drug release control, Tween $80(1.0 \% \mathrm{w} / \mathrm{v})$ was added to the dissolution medium for the in vitro drug release studies of tablets containing $50 \mathrm{mg}$ of propranolol. $\mathrm{HCl}$. No differences were observed between drug amount release of propranolol.HCl 50-mg tablets with and without addition of Tween 80 to the dissolution medium, which confirms this hypothesis $(p=0.0732)$, indicating that the lipid solubility plays an important role in drug diffusion, without any indication of solvent penetration effect in the control of drug release.

At the same time, a decrease in the propranolol. $\mathrm{HCl}$ load in the tablets, 50 to $15 \mathrm{mg}$, was investigated. No Tween was added to the dissolution medium. The comparison of the results obtained with those produced with propranolol.HCl 50-mg and 15-mg tablets showed a lower propranolol. $\mathrm{HCl}$ release for the tablets with low drug content (15mg).

It was noticed that there was a lower drug release rate from tablets with propranolol.HCl than from the ones containing theophylline (Figure 4), and since theophylline and propranolol. $\mathrm{HCl}$ have similar molecular volume (two rings fused systems) and molecular weight (propranolol. $\mathrm{HCl} 295 \mathrm{~g}$ and theophylline $180 \mathrm{~g}$ ), probably only the propranolol.HCl lipid solubility is responsible for the reduction in drug release.

\section{Evaluation of water uptake profiles of MSG, chitosan and Xanthan Gum in water, SGF and SIF}

The preparation of new cross-linking MSG hydrogels, was conducted with the intention of modulating their drug extended-release profile. The choice of the new hydrogel composition was made in order to introduce ionic moieties in the polymer structure to increase its swelling, searching at the same time, a suitable zero order drug release kinetics. Therefore, the water uptake and extendedrelease profile of two well-known efficient hydrophilic matrices, chitosan and xanthan gum (Talukdar et al., 1995) were investigated and the results obtained with these studies were used as parameters to determine the advantages of their adequate association with MSG. It was possible to observe an intense reduction of water uptake of chitosan, in SGF or SIF, indicating a great influence of ionic strength on polysaccharide swelling. This behavior was not observed with xanthan gum, which did not show an appreciable reduction of water uptake despite the dissolution medium. However, with MSG an increase of water uptake rate and hydrogel volume were observed when an ionic medium was used (Figure 5).

\section{Evaluation of the model drug rate release profiles from chitosan and xanthan gum tablets}

The comparative in vitro drug release studies with chitosan and xanthan gum tablets were carried out using theophylline as model drug. When SGF was used as dissolution medium, the lowest theophylline release amount was observed with chitosan tablets, despite of their low water uptake values. A very similar extendedrelease profile was observed with MSG and xanthan gum in this dissolution medium. The change of $\mathrm{pH}$ (SIF) produced a remarkable change in behavior; a very high theophylline release was observed in chitosan tablets and a remarkable drug retarding ability registered to xanthan

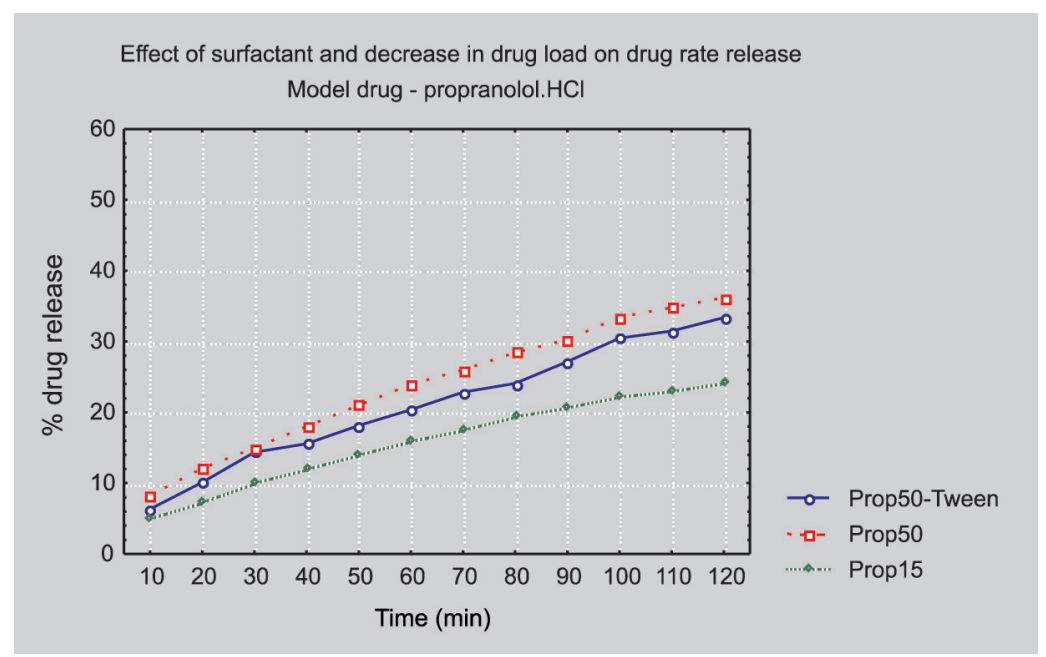

FIGURE 4 - Investigation of the effect of addition of surfactant and decrease in drug load on drug release profile. 


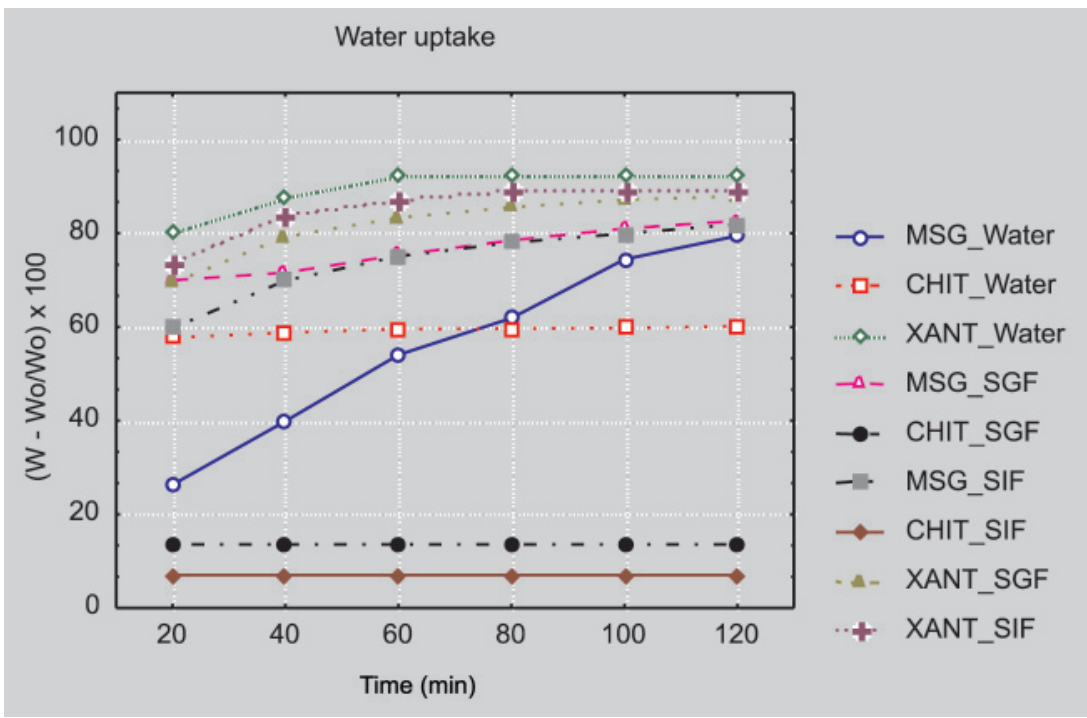

FIGURE 5 - Dynamic water uptake for MSG, chitosan and xanthan gum in water, SGF and SIF.

gum tablets (Figure 6). This apparent discrepancy in drug release profiles observed in chitosan tablets in SGF and SIF in comparison to the other polysaccharides used could be attributed to drug dissolution or to a matrix erosion of chitosan tablets, taking their low swelling into consideration.

An intense erosion feature was detected in chitosan tablets $(59.0 \%)$ when compared to values of 25.3 and $27.7 \%$ obtained for MSG and xanthan respectively. The drug release in SGF from tablets in the three polymers studied could be considered linear with the time (i.e., zero order kinetics). The major correlation coefficient was obtained with MSG tablets, but very similar to the results verified for chitosan and xanthan gum. When using SIF as dissolution medium the zero order kinetic was not observed after $60 \%$ release in all cases, but a good correlation could be observed for xanthan gum tablets at the first $40 \%$ release (Table III).
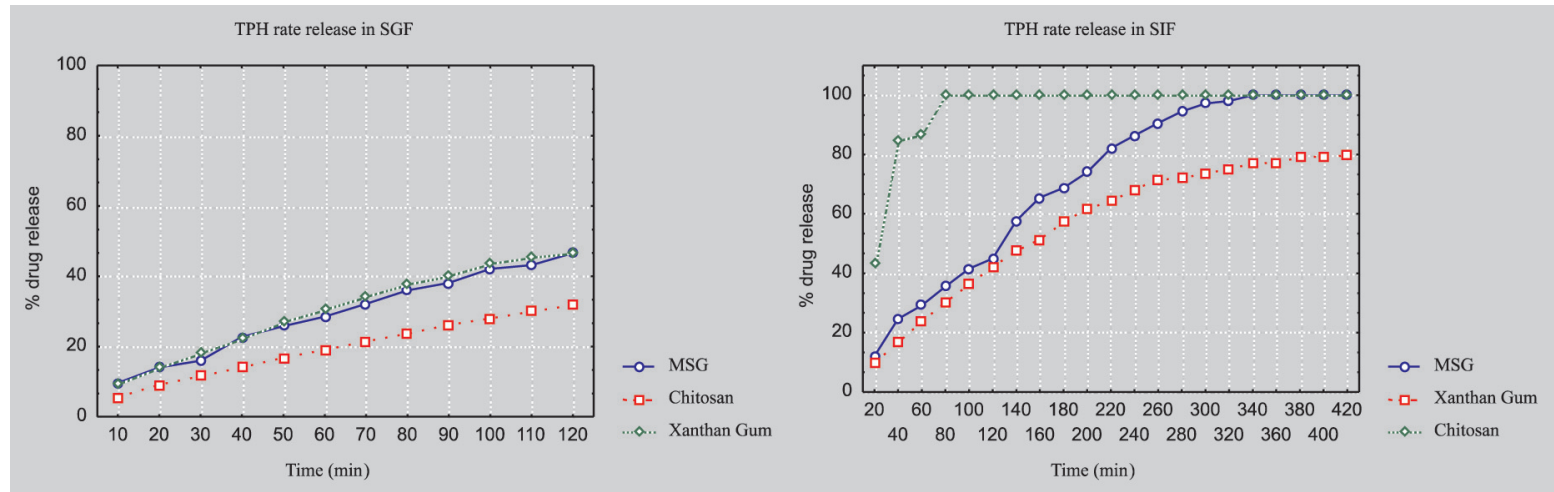

FIGURE 6 - Comparison of TPH release behavior in SGF and SIF from chitosan, MSG and xanthan gum tablets.

TABLE III - Drug release kinetics observed in Chitosan, MSG and Xanthan Gum matrices in SGF and SIF.

\begin{tabular}{lccc}
\hline Polysaccharide & SGF/120 min & $\begin{array}{c}\text { Correlation Coefficient (r) } \\
\text { SIF/420 min }\end{array}$ & SIF/120 min \\
\hline Chitosan & 0.9863 & 0.5087 & 0.8317 \\
MSG & 0.9913 & 0.9524 & 0.9648 \\
Xanthan gum & 0.9812 & 0.9526 & 0.9984 \\
\hline
\end{tabular}




\section{Selecting the agent for cross-linking reactions}

From these results, it was possible to assume that MSG Chitosan or MSG Xanthan Gum associations could be able to produce the extended-release profile desired by means of the complementary drug release characteristics of these polysaccharides. It was then proposed the synthesis of various new polysaccharides networks, using 1:1, 1:2 and 2:1 MSG_Chitosan and MSG_Xanthan gum ratios. The first step of this activity was the investigation of the best cross-linking agent and its ideal concentration, considering as parameter the extended-release profile achieved with glutaraldehyde (Gliko-kabir et al., 1998) and HMDI(Wu et al., 1998) reactions with MSG, the initial material for all cross-linking reactions and chitosan due it high reactivity. The dynamic water uptake of cross-linked polysaccharides exhibited in aqueous medium did not show significant differences when 5,10 and $15 \% \mathrm{w} / \mathrm{w}$ glutharadehyde were used as cross-linking agent for MSG. An appreciable reduction was obtained when the glutharaldehyde concentration was increased to 20 and $40 \% \mathrm{w} / \mathrm{w}$ (Table IV). The use of HMDI only produced a significant water uptake reduction at $40 \% \mathrm{w} / \mathrm{w}$ concentration. It was possible to detect some erosion only when $40 \% \mathrm{w} / \mathrm{w}$ of glutharadehyde was used (19.0\%). The reaction products of HMDI/MSG cross-linking did not show a significant erosion reduction. The theophylline drug release rate from glutharaldehyde cross-linked polymers increased in all cases, but the values noted with 5 to $15 \% \mathrm{w} / \mathrm{w}$ concentration were not significantly different. At $40 \%$ and $20 \% \mathrm{w} / \mathrm{w}$ a high increase of drug release was noticed.

TABLE IV - Characterization of cross-linked MSG-GA and MSG-HMDI polymers considering their extended-release profile

\begin{tabular}{lccc}
\hline Polymer & $\begin{array}{c}\text { Water } \\
\text { uptake } \\
(\mathbf{\%})\end{array}$ & $\begin{array}{c}\text { Erosion } \\
\mathbf{( \% )}\end{array}$ & $\begin{array}{c}\text { TPH } \\
\text { release (\%), } \\
\text { in SGF }\end{array}$ \\
\hline MSG & 79.45 & 25.30 & 46.63 \\
MSG-GA5 & 80.07 & 25.00 & 51.99 \\
MSG-GA10 & 80.82 & 24.80 & 51.55 \\
MSG-GA15 & 79.55 & 25.00 & 51.98 \\
MSG-GA20 & 73.68 & 22.50 & 57.93 \\
MSG-GA40 & 73.45 & 19.00 & 62.91 \\
MSG-HMD5 & 80.81 & 25.01 & 50.55 \\
MSG-HMDI10 & 80.07 & 25.20 & 50.25 \\
MSG-HMD15 & 80.06 & 25.4 & 49.93 \\
MSG-HMDI20 & 80.03 & 25.00 & 50.59 \\
MSG-HMDI40 & 75.98 & 23.00 & 49.88 \\
\hline
\end{tabular}

The effect of HMDI in theophylline drug release rate was lower than that of glutharaldehyde. The statistical analysis of the experiments using different HMDI concentrations did not show significant differences in the results (Table IV). The reaction of chitosan in acetic acid solution with glutharaldehyde in all concentrations led to an intense water uptake reduction and polymer erosion resulting in a complete release of theophylline after 90 $\mathrm{min}$. An intense gel formation was detected in the reaction medium when using $40 \% \mathrm{w} / \mathrm{v}$ glutharadehyde concentration. It was not possible to observe any sign of the reaction when HMDI was used as cross-linking agent, probably due to its hydrolysis in aqueous acidic medium (Table V) (Castro et al., 1985).

TABLE V - Characterization of cross-linked Chitosan-GA polymers regarding its extended-release profile

\begin{tabular}{lccc}
\hline Polymer & $\begin{array}{c}\text { Water } \\
\text { uptake } \\
(\mathbf{\% )}\end{array}$ & $\begin{array}{c}\text { Erosion } \\
\mathbf{( \% )}\end{array}$ & $\begin{array}{c}\text { TPH } \\
\text { release (\%), } \\
\text { in SGF }\end{array}$ \\
\hline Chitosan & 61.00 & 59.00 & 48.00 \\
Chitosan-GA5 & 56.00 & $>70$ & 100.00 \\
Chitosan-GA10 & 57.50 & $>70$ & 100.00 \\
Chitosan-GA15 & 56.33 & $>70$ & 100.00 \\
Chitosan-GA20 & 55.00 & $>70$ & 100.00 \\
\hline
\end{tabular}

From these results, it was possible to conclude that only glutaraldehyde can be used as cross-linking agent at $5.0 \%(\mathrm{w} / \mathrm{w})$ concentration, considering that no remarkable change was noticed in the polysaccharide drug extendedrelease profile. Then, the cross-linking reaction was made with MSG_chitosan mixtures, using glutharadehyde as cross-linking agent and 1:1, 1:2 and 2:1 polymer ratios. In order to evaluate the compatibility of the two polysaccharides, the physical mixture was previously prepared. A total disintegration of the tablets after $60 \mathrm{~min}$. was noted with the physical mixture. The increase of chitosan amount in the mixture (1:2 ratio) did not change the polymer water uptake profile. However, a great increase in water uptake was obtained as consequence of the higher MSG content (2:1 ratio) in the mixture (Table VI).

\section{Polymeric matrices of MSG_Chitosan}

The best theophylline release profile in SGF was obtained with the MSG Chitosan 1:1 polymer ratio, showing lower theophylline release rate than that observed with the tablets made with MSG, and similar to 
TABLE VI - Comparative evaluation of dynamic water uptake for new cross-linked matrices

\begin{tabular}{lc}
\hline Polymer & Water uptake (\%) \\
\hline MSG_Chitosan 1:1 & 64.57 \\
MSG_Chitosan 1:2 & 65.08 \\
MSG_Chitosan 2:1 & 76.31 \\
Physical mixture & tablet disintegration \\
MSG & 79.45 \\
Chitosan & 61.00 \\
\hline
\end{tabular}

the one of tablets made with chitosan, with a good fit to zero order drug release kinetics $(r=0.9956)$, more adequate than it was observed with the isolated polymers. Using this polymer ratio, an ideal balance between MSG and chitosan drug retarding characteristics was obtained in SGF dissolution medium. An increase in theophylline release rate was observed with the increase of MSG content in the mixture (2:1 ratio). It was possible to observe an $80 \%$ theophylline release from the physical mixture tablets after 60 min (Figure 7). No significant difference could be detected in the IR spectra of cross-linking polysaccharides and the physical mixture, even though it is not the more appropriate technique to evaluate the success of crosslinking reactions.

However, the use of Simulated Intestinal Fluid as dissolution medium led to an appreciable faster theophylline release from MSG_Chitosan 1:1 matrices (74.99\% at $120 \mathrm{~min}$ and $95.02 \%$ at $240 \mathrm{~min}$ ), much slower than that obtained with chitosan (100\% at $120 \mathrm{~min})$, but faster than the MSG matrix. The MSG_Chitosan 2:1 polymer ratio matrix was also tested (the larger MSG concentration would probably be able to improve network drug retarding ability in SIF), yielding almost invariable results $(72.30 \%$ at $120 \mathrm{~min}$ to 91.32 at $240 \mathrm{~min}$.). It is well known that an increase in the molecular weight of chitosan used for extended-release purposes promotes the increasing of its efficiency. So the substitution of the medium molecular weight chitosan by the high molecular weight could improve the extended-release profile of the cross-linking polysaccharides. However, an intense erosion and faster theophylline release were observed in all matrices prepared with high molecular weight chitosan, indicating that the increase of molecular weight led to a reduction of cross-linking reactions favoring the reaction within the chitosan chains.

\section{MSG Xanthan Gum matrices}

The substitution of chitosan by xanthan gum in MSG cross-linking reactions was investigated in the same polymer ratios previously used. All products obtained were analyzed by IR spectrometry. The spectra confirmed that this technique is not capable of distinguish physical mixtures from cross-linked matrices.

To effectively confirm the success of these crosslinking reactions we made use of DSC technique. The figure 8 shows the thermograms of the physical mixture of MSG and xanthan gum as well as those of the new blends prepared. The physical mixtures show two endothermic peaks at $110{ }^{\circ} \mathrm{C}$ (corresponding to the loss of the water content of polysaccharides) and $190{ }^{\circ} \mathrm{C}$ (due to the chain

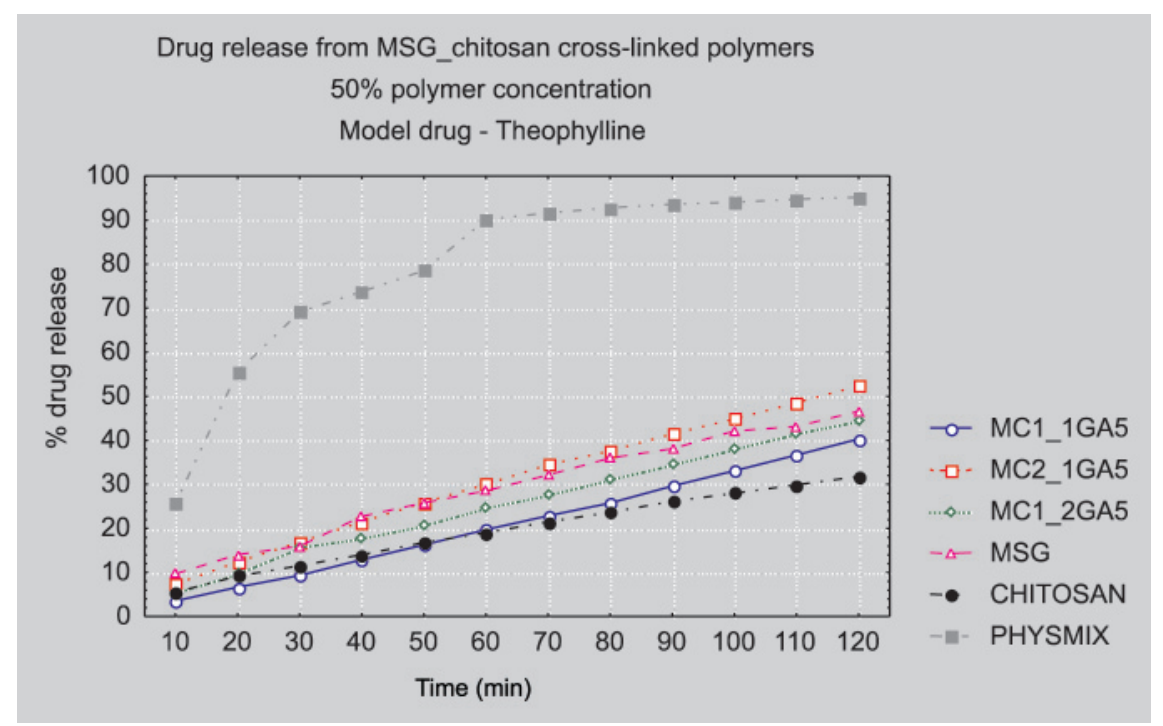

FIGURE 7 - Drug release profile of MSG_Chitosan cross-linked polymers matrices, in SGF. 
relaxation and polymer molification). However, the first peak disappeared in the case of new blends prepared and the second peak appeared at $240{ }^{\circ} \mathrm{C}$ indicating the formation of new polymeric entity.

The water uptake profile of the new xanthan gum cross-linked polymers showed that the presence of xanthan gum in the matrix led to a faster water uptake (Figure 9). The statistical evaluation of the results showed no significant differences between the $1: 1$ and $2: 1$
MSG_Xanthan Gum matrices water uptake behavior, as no differences were observed in the final hydrogel volume in all cases studied.

These results showed a very closer swelling behavior for all cross-linked MSG_Xanthan Gum matrices, indicating that the matrix swelling was not hindered by cross-linking reaction. By comparing the amount of theophylline release from the new MSG_Xanthan Gum matrices and isolated polysacchari-

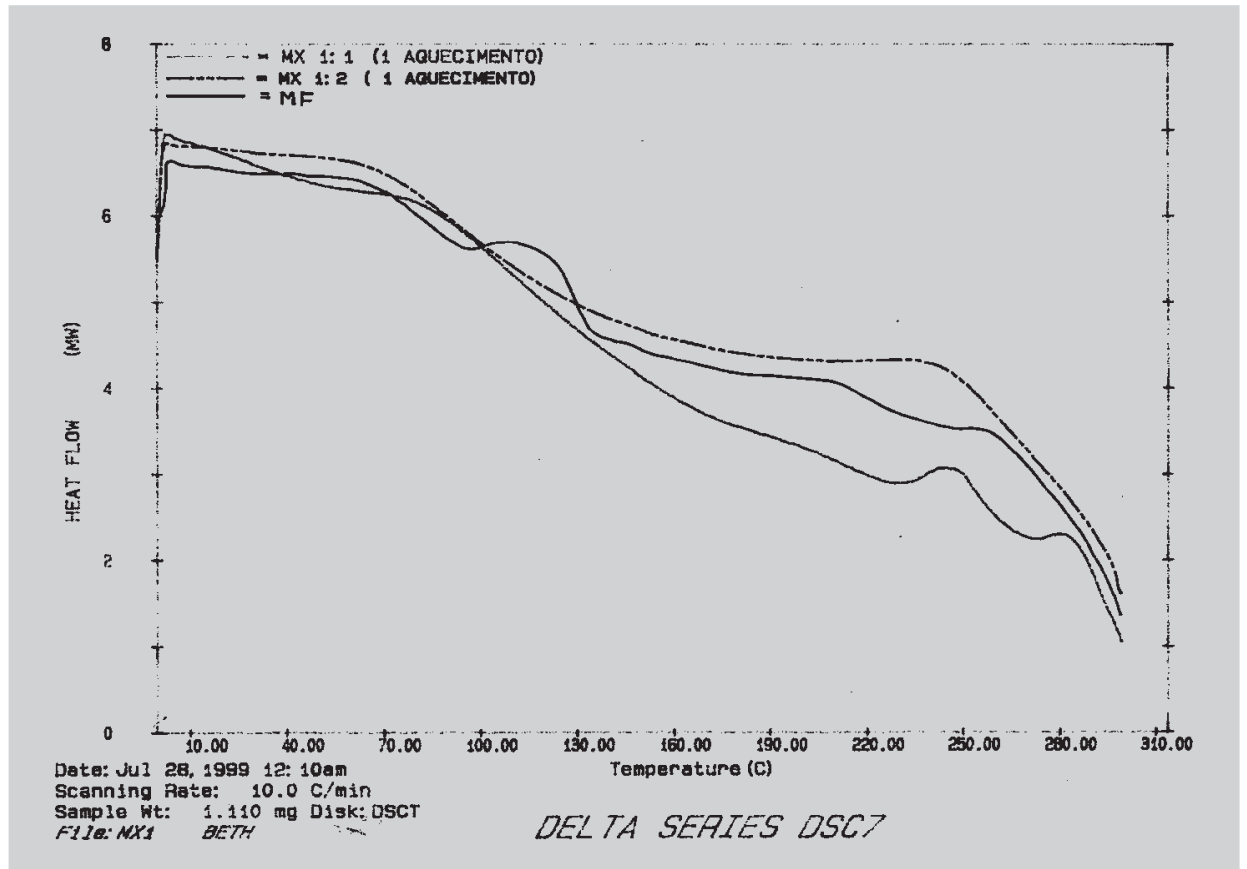

FIGURE 8 - DSC analysis of MSG_Xanthan Gum cross-linked products: Red - MSG_Xanthan Gum 1:2 - Brown MSG_Xanthan Gum 1:1 - Blue- MF (Physical mixture).

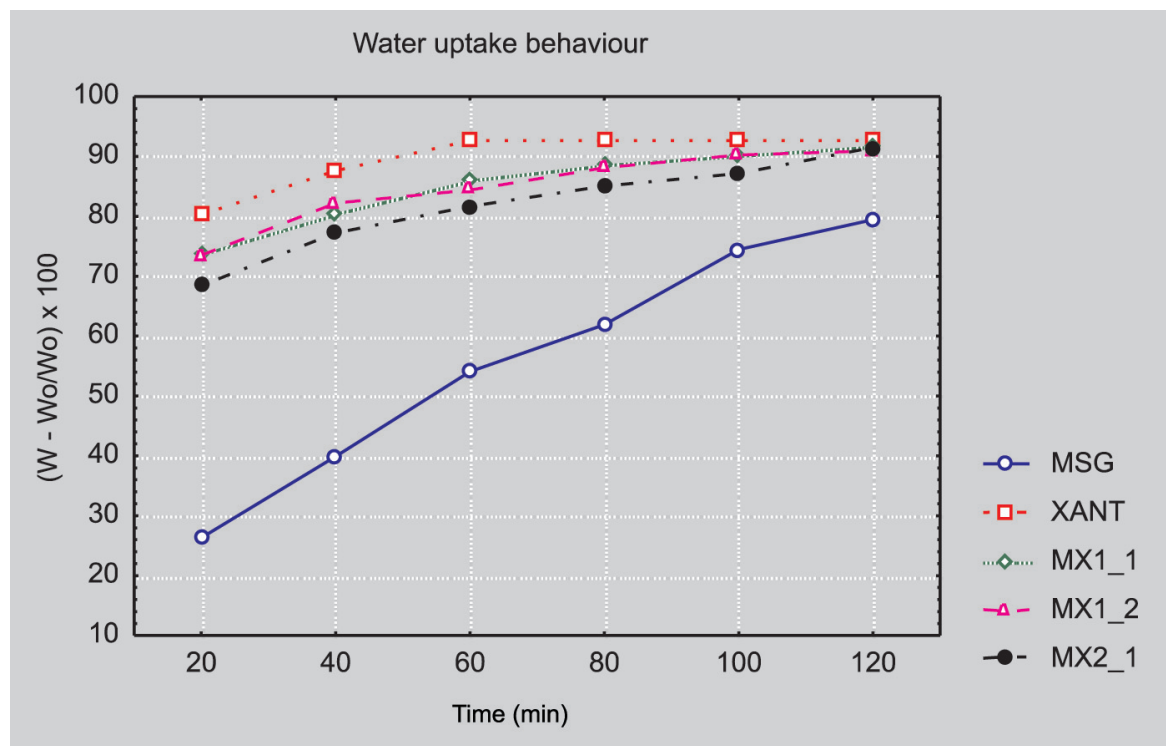

FIGURE 9 - Dynamic water uptake profile of MSG, xanthan gum and cross-linked matrices. 
des in SGF, it was possible to observe a lower drug release from MSG_Xanthan Gum 1:1 and 1:2 polymer ratio products than all matrices investigated. There was difference between the drug release rate from MSG_Xanthan Gum 2:1 polymer ratio mixtures and xanthan gum tablets $(\mathrm{p}=0.6197)$, indicating that the increase of MSG concentration in the mixture led to a consequent increase in drug release (Figure 10).

The best fit to zero order kinetics was observed in the mixture with the highest MSG content (Table VII), but a good correlation could be found in all new cross-linking polysaccharides (better than in the isolated polymers). As the $1: 1$ and $1: 2$ polymer ratio matrices did not show significant differences in their theophylline drug release rate in SGF, and the best correlation to zero order kinetics was noted with the 1:2 polymer ratio, this could be considered the best polymer ratio for extended-release purposes.

TABLE VII - Correlation to zero order drugs release kinetics observed for the cross-linked MSG_Xanthan Gum matrices in SGF

\begin{tabular}{lc}
\hline Polysaccharide & $\begin{array}{c}\text { Correlation coefficient (r) } \\
\text { SGF 120 min }\end{array}$ \\
\hline MSG_Xanthan Gum (1:1) & 0.9858 \\
MSG_Xanthan Gum (2:1) & 0.9962 \\
MSG_Xanthan Gum (1:2) & 0.9934 \\
MSG & 0.9913 \\
Xanthan Gum & 0.9812 \\
\hline
\end{tabular}

However, the investigation of theophylline release profile in SIF from 1:1 and 1:2 polymer ratio mixture matrices showed different results from those observed in these same matrices with the use of SGF. Similar theophylline release rates were obtained from both polymers mixtures at the first $120 \mathrm{~min}(\mathrm{p}=0.0714)$, but an expressive increase in drug release was observed in the 1:2 polymer ratio mixture after this period (Figure 11). Both matrices showed a better drug retarding ability than xanthan gum, the best result being observed with 1:1 polymer ratio mixture. A little increase of TPH release was also observed with 1:2 polymer ratio mixture matrix after $380 \mathrm{~min}$, which led to a final theophylline release rate higher than that observed in xanthan gum tablets, yielding a consequent higher total theophylline drug release rate. From these results, it was possible to state that the MSG matrix component was able to modulate the erosion/ swelling balance of the mixture in combination with the xanthan gum at $1: 1$ and $1: 2$ polysaccharide ratio, producing a new efficient extended-release matrix (Sujjaareevath, 1998). The drug release kinetics observed in these new matrices did not follow the zero order approach for drug release control, but a better correlation could be observed in both of the two new polymers in comparison to the isolated polysaccharides in SIF for $420 \mathrm{~min}$, dissolution experiments and adequate fit until $60 \%$ drug release (Table VIII). Considering the total theophylline release amount in SGF and SIF, as well as the better correlation to the zero order of its dissolution experiments results, it was possible to conclude that the MSG_Xanthan Gum 1:2 matrix is the best new extended-release hydrophilic matrix.

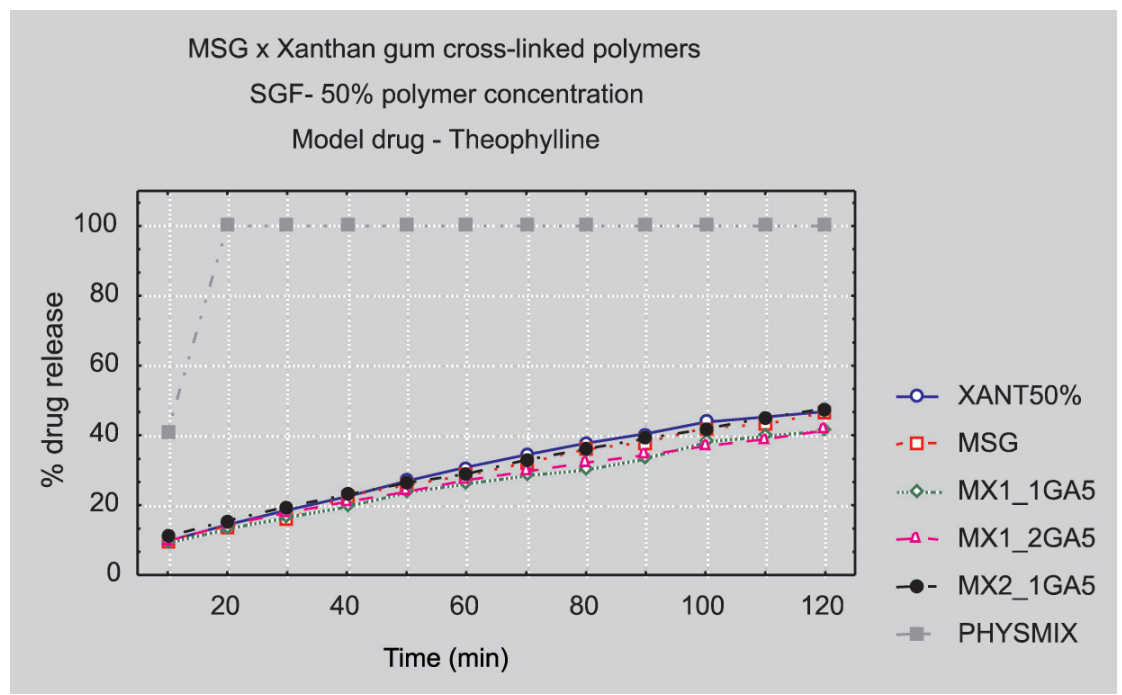

FIGURE 10 - Comparative drug release profile evaluation of MSG, xanthan gum and cross-linked matrices in SGF. 


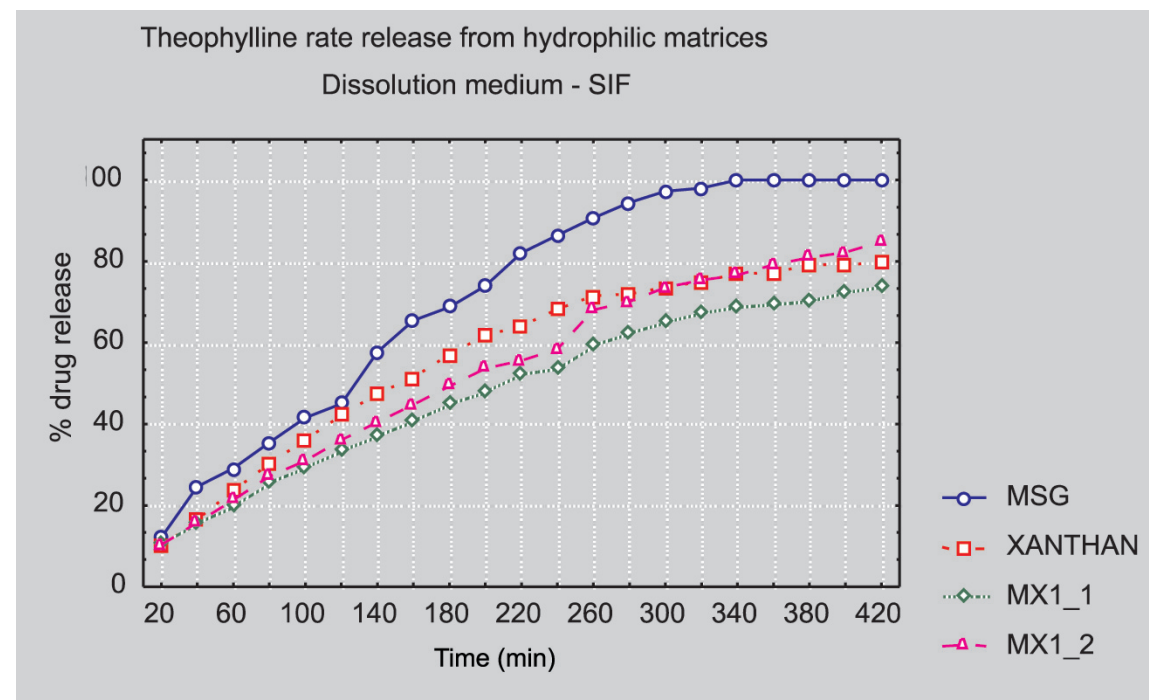

FIGURE 11 - Comparative evaluation of drug release profile for MSG, xanthan gum and cross-linked matrices, in SIF.

TABLE VIII - Correlation to zero order drugs release kinetics observed for the cross-linked MSG_Xanthan Gum matrices in SIF

\begin{tabular}{lc}
\hline Polysaccharide & $\begin{array}{c}\text { Correlation coefficient (r) } \\
\text { SIF 420 min }\end{array}$ \\
\hline MSG_Xanthan Gum (1:1) & 0.9840 \\
MSG_Xanthan Gum (1:2) & 0.9868 \\
MSG & 0.9524 \\
Xanthan Gum & 0.9526 \\
\hline
\end{tabular}

\section{Evaluation of drug delivery control mechanism}

The evaluation of the drug delivery control mechanism observed for MSG_Xanthan Gum 1:2 matrix was done with the same experiment used for the MSG matrix, when salicylic acid and its sodium salt were evaluated using SGF as dissolution medium. As the drug release amount expressed as a function of time showed the same result in both drugs $(p=0.3147)$, the solvent penetration did not have any influence in drug release control (Figure 12).

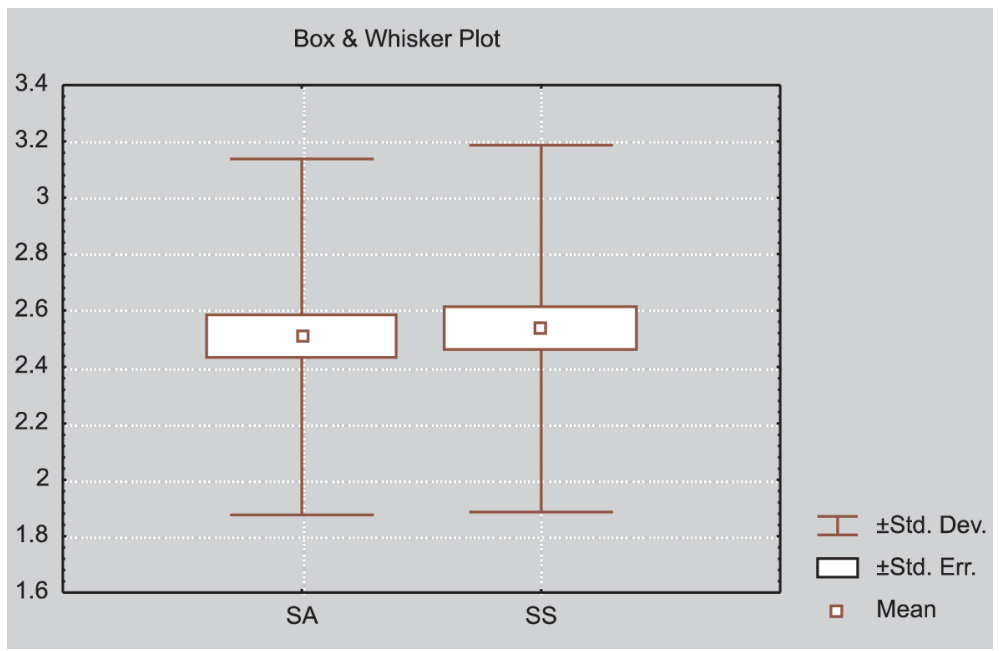

FIGURE 12 - Drug release amount observed from salicylic acid/sodium salicylate tablets prepared with MSG_Xanthan Gum 1:2 polymer in SGF. 
Evaluation of drug release kinetics and delivery control mechanism from MSG_Xanthan Gum 1:2 matrix

The data of tables IX and X were plotted according to equations 1-4. From the linear portions of the curve, slope, intercept and correlation coefficient (r) were calculated. The data are summarized in tables XI and XII. With the zero order plots, the linearity was noted with matrix 1:2 in SIF. The data yielded an apparently straight line with zero order as well as with first order kinetics. The correlation coefficients were high $(\mathrm{r}=0.999)$. With the Higuchi equation and the RRSBW fit, the curve showed a straight line, but the correlation coefficients were low, indicating lack of linear correlation between the variables. In Simulated Gastric Fluid, the MSG_XG 1:2 matrix presented a low value for the correlation coefficient $(\mathrm{r}=$ 0.997 ) for the zero order plot, indicating lack of linear correlation. Linearity was noted with First Order, Higuchi equation and RRSBW distribution. The correlation coefficients were very high $(r=0.999)$.
TABLE IX - Fractional theophylline release versus time from a MSG_Xanthan Gum 1:2 ratio in SGF.

\begin{tabular}{cc}
\hline Time (min) & Fractional drug release $\left(\mathbf{M}_{\mathbf{t}} / \mathbf{M}_{\infty}\right)$ \\
\hline 10 & 0.097 \\
20 & 0.143 \\
30 & 0.179 \\
40 & 0.209 \\
50 & 0.238 \\
60 & 0.271 \\
70 & 0.297 \\
80 & 0.322 \\
90 & 0.344 \\
100 & 0.369 \\
110 & 0.414 \\
120 & 0.431 \\
\hline
\end{tabular}

TABLE X - Fractional theophylline release versus time from a MSG_Xanthan Gum 1:2 ratio in SIF

\begin{tabular}{cccc}
\hline Time $(\mathbf{m i n})$ & Fractional drug release $\left(\mathbf{M}_{\mathbf{t}} / \mathbf{M}_{\infty}\right)$ & Time $(\mathbf{m i n})$ & Fractional drug release $\left(\mathbf{M}_{\mathbf{t}} / \mathbf{M}_{\infty}\right)$ \\
\hline 20 & 0.103 & 240 & 0.584 \\
40 & 0.157 & 260 & 0.680 \\
60 & 0.213 & 280 & 0.701 \\
80 & 0.271 & 300 & 0.735 \\
100 & 0.310 & 320 & 0.754 \\
120 & 0.360 & 340 & 0.766 \\
140 & 0.404 & 360 & 0.792 \\
160 & 0.447 & 380 & 0.809 \\
180 & 0.492 & 400 & 0.822 \\
200 & 0.536 & 420 & 0.848 \\
220 & 0.556 & & \\
\hline
\end{tabular}

TABLE XI - Kinetics of theophylline from MSG_XG 1:2 matrix tablets in SGF with regression analysis with all the data of the experiment

\begin{tabular}{cccccc}
\hline Slope (k) & $\begin{array}{c}\text { Zero Order } \\
\text { Correlation } \\
\text { Coefficient }\end{array}$ & $\begin{array}{c}\text { Degrees of } \\
\text { Freedom }\end{array}$ & Slope (k) & $\begin{array}{c}\text { First Order } \\
\text { Correlation } \\
\text { Coefficient }\end{array}$ & $\begin{array}{c}\text { Degrees of } \\
\text { Freedom }\end{array}$ \\
\hline 0.293 & 0.997 & 10 & -0.004 & -0.999 & 10 \\
\hline Slope $(\mathrm{k})$ & $\begin{array}{c}\text { Higuchi Equation } \\
\text { Correlation } \\
\text { Coefficient }\end{array}$ & $\begin{array}{c}\text { Degrees of } \\
\text { Freedom }\end{array}$ & Slope (k) & $\begin{array}{c}\text { RRSB Distribution } \\
\text { Correlation } \\
\text { Coefficient }\end{array}$ & $\begin{array}{c}\text { Degrees of } \\
\text { Freedom }\end{array}$ \\
\hline 4.266 & 0.999 & 10 & 0.685 & 0.999 & 10 \\
\hline
\end{tabular}


TABLE XII - Kinetics of theophylline from MSG_XG 1:2 matrix tablets in SIF with regression analysis over the first $60 \%$ of drug release

\begin{tabular}{cccccc}
\hline Slope (k) & $\begin{array}{c}\text { Zero Order } \\
\text { Correlation } \\
\text { Coefficient }\end{array}$ & $\begin{array}{c}\text { Degrees of } \\
\text { Freedom }\end{array}$ & Slope (k) & $\begin{array}{c}\text { First Order } \\
\text { Correlation } \\
\text { Coefficient }\end{array}$ & $\begin{array}{c}\text { Degrees of } \\
\text { Freedom }\end{array}$ \\
\hline 0.238 & 0.999 & 8 & -0.004 & -0.999 & 8 \\
\hline Slope (k) & $\begin{array}{c}\text { Higuchi Equation } \\
\text { Correlation } \\
\text { Coefficient }\end{array}$ & $\begin{array}{c}\text { Degrees of } \\
\text { Freedom }\end{array}$ & Slope (k) & $\begin{array}{c}\text { RRSBW Distribution } \\
\text { Correlation } \\
\text { Coefficient }\end{array}$ & $\begin{array}{c}\text { Degrees of } \\
\text { Freedom }\end{array}$ \\
\hline 4.552 & 0.995 & 8 & 0.856 & 0.996 & 8 \\
\hline
\end{tabular}

By evaluating the fractional theophylline release versus time (Figures 13 and 14), and calculating the diffusion exponent in both media, it was possible to conclude that the drug release control for this new hydrophilic matrix in SIF and SGF followed an anomalous kinetics (Table XIII).

TABLE XIII - Values found for diffusion exponent and kinetic constant over the first $60 \%$ of theophilline release from tablets containing MSG_Xanthan Gum in 1:2 ratio

\begin{tabular}{ccc}
\hline $\begin{array}{c}\text { Dissolution } \\
\text { Medium }\end{array}$ & $\begin{array}{c}\text { Kinetic } \mathbf{k} \\
\text { constant } \\
\left(\mathbf{m i n}^{-\mathbf{n}}\right)\end{array}$ & Exponent (n) \\
\hline SGF & 0.024 & 0.598 \\
SIF & 0.011 & 0.725 \\
\hline
\end{tabular}

\section{CONCLUSIONS}

It was possible to observe in this work that a combination of distinct hydrophilic matrices through cross-linking allows the combination of synergic properties of MSG and xanthan gum (XG) to originate a new entity with retarding properties and drug release kinetics superior to those given by their isolated constituents. A better combination was obtained with a mixture of MSG and xanthan gum, with mass ratio of 1:2, using $5,0 \% \mathrm{w} / \mathrm{w}$ glutharaldehyde aqueous solution as cross-linking agent. Both the release profiles of theophylline in SIF as in SGF reported more suitable with those introduced towards isolated polysaccharides. In this new matrix zero order kinetics is prevalent, which is ideal for an extended-release system. These results lead to conclusion that this methodology will be applicable for the preparation of other new hydrophilic matrix systems, with

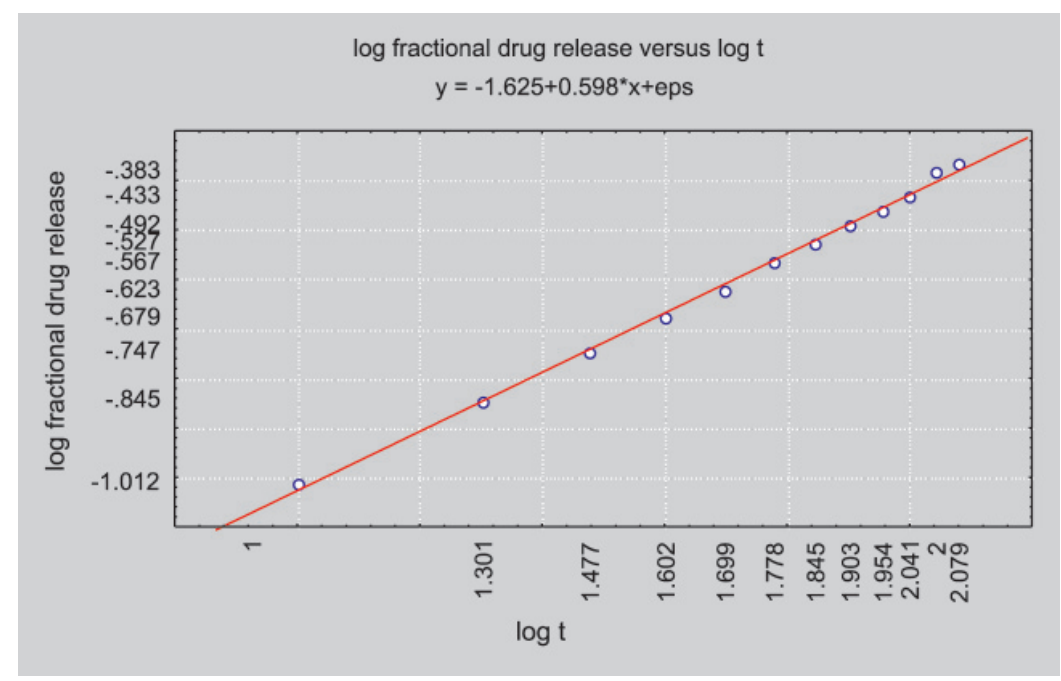

FIGURE 13 - Plot of log fractional drug release versus log t over the first $60 \%$ of drug release from a matrix containing MSG_XG in 1:2 ratio-SGF. 


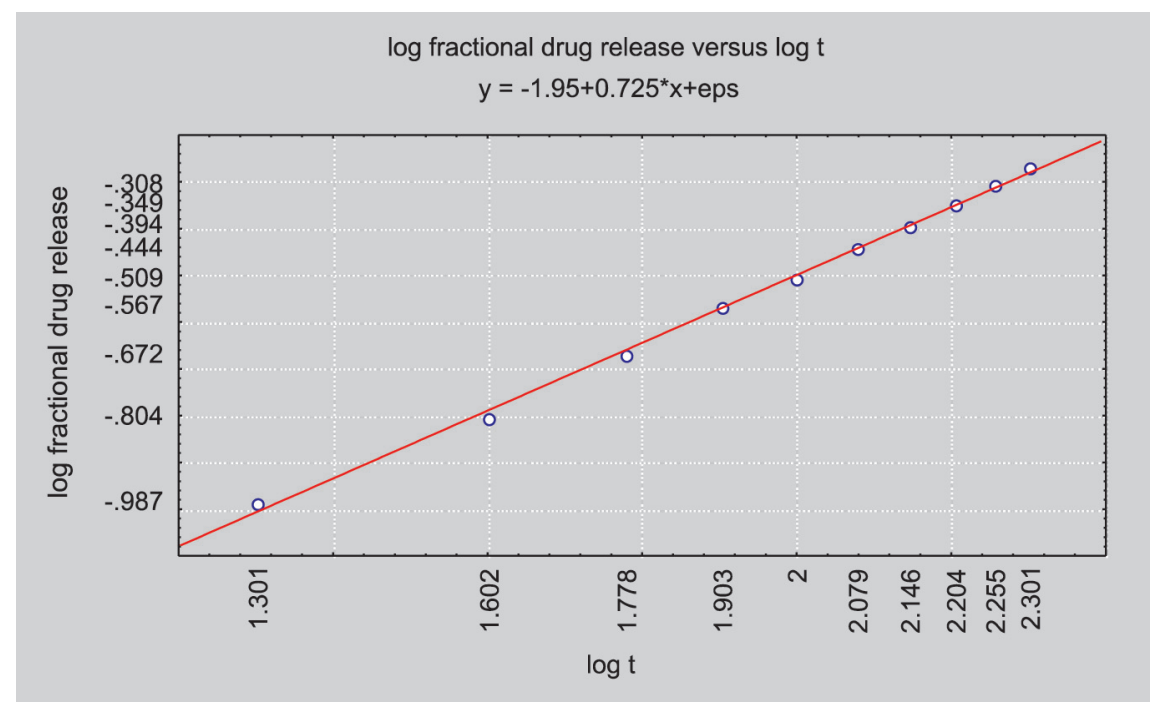

FIGURE 14 - Plot of $\log$ fractional drug release versus $\log t$ over the first $60 \%$ of drug release from matrix containing MSG_XG in 1:2 ratio-SIF.

better characteristics than those reported by isolated constituents.

\section{RESUMO}

\section{Estudo da utilização de polissacarídeos no desenvol- vimento de formulações de liberação prolongada: goma de semente de algaroba, goma xantana e quitosano}

O objetivo deste trabalho foi o desenvolvimento de novos sistemas de matrizes hidrofilicas através da formação de ligações cruzadas (cross-linking) entre a Goma da Semente da Algaroba (GSA), uma galactomanana que ocorre no endosperma das sementes de uma árvore nativa do Brasil, a Prosopis juliflora $D C$, e dois polissacarídeos bem conhecidos pela sua habilidade de retardar a liberação de fármacos, quitosano e goma xantana, visando a utilização das novas substâncias na preparação de formas orais de liberação prolongada. O estudo iniciou com a avaliação da funcionalidade GSA como matriz hidrofilica. A seguir, iniciamos o estudo do perfil de absorção de água dos polímeros envolvidos (GSA, Quitosana e goma xantana), nos seguintes meios: água, SGF e SIF. Na etapa seguinte, procuramos pelo melhor agente formador de ligação cruzada, entre os dois encontrados em literatura, glutaraldeído (GA) e hexametilenodiisocianato (HMDI). Sendo que a GA se apresentou como o melhor agente pelos resultados apresentados. O próximo passo foi a preparação e avaliação de novas matrizes hidrofílicas de GSA_Quitosana e
GSA_Goma Xantana, com proporções diferentes, 1:1, 1:2 e 2:1. Finalmente, após a escolha do sistema hidrofilico que apresentou os melhores resultados, utilizando as ferramentas estatísticas, investigamos o mecanismo de controle da liberação do fármaco modelo. Por fim concluímos que a melhor combinação de polissacarídeos foi conseguida com a GSA e a goma xantana, na proporção de 1:2, utilizando solução de glutaraldeído como agente de formação de ligação cruzada. Esta nova matriz apresentou cinética de ordem zero, que é fundamental em uma substância a ser utilizada em formulações orais sólidas de liberação prolongada.

UNITERMOS: Goma de Semente de Algaroba (GSA). Quitosano. Goma Xantana. Matrizes hidrofílicas. Reações de ligação cruzada. Formas orais de liberação prolongada

\section{ACKNOWLEDGMENTS}

We would like to thank FAPERJ-Brazil (Fundação de Amparo a Pesquisa do Estado do Rio de Janeiro) and MURST-Italy for the financial support that allowed the conclusion of this work.

\section{REFERENCES}

ACARTÜRK, F. A. Preparation of prolonged-release tablet formulation of diclofenac sodium part 1: Using chitosan, Pharmazie, Eschborn, v.44, p.547-549,1989. 
ALHAIQUE, F.; BELTRAMI, E.; RICCIERI, F. M.; SANTUCCI, E.; TOUITOU, E. Scleroglucan sustained released oral preparations. Part I. In vitro experiments. Drug Dev. Delivery, v. 5, p.249-257, 1989.

CARSTENSEN, J. T. Pharmaceutical principles of solid dosage forms. Lancaster: Thecnomi publish co., 1987. $392 p$.

CASTRO, E. A.; MOODIE, R. B.; SANDON, P. J. The kinetics of hydrolysis of methyl and phenyl isocyanates. J. Chem. Soc. Perkin Trans. II, Letchworth, p. 737-738, 1985.

CAVALCANTI, O. A.; CABRAL, L. M.; BAUDNER, B. C.; MURTAS, E.; RICCIERI, F. M.; ALHAIQUE, F. A galactomannan from the seeds of Prosopis juliflora DC; studies for a new sustained release matrix. Acta Technol. Legis Med., Parma, v. 9, n.3, p. 149-159, 1998.

COVIELlO, T.; DENTINI, M.; RAMBONE, G.; DESIDERI, P.; CARAFA, M.; MURTAS, E.; RICCIERI, F. M.; ALHAIQUE, F. A novel cocrosslinked polysaccharide: studies for a controlled delivery matrix. J. Controlled Release, Amsterdam, v. 55, p.57-66, 1998.

FELT, O.; BURI, P.; GURNY, R. Chitosan; a unique polysaccharide for drug delivery. Drug Dev. Ind. Pharm., v. 24, n.11, p. 979-973, 1999.

GLIKO-KABIR, T.; YAGEN, B.; PENHASI, A.; RUBINSTEIN, A. Low swelling crosslinked guar and its potential use as colon -specific drug carrier. Pharm. Res., v. 15, n.7, p. 1019-1025, 1998.

LAPIDUS, H.; LORDI, N. G. Drug release compressed hydrophilic matrices. J. Pharm. Sci., Washington, p. 1292-1301, 1968.

LEE, P. I. Effect of non-uniform drug concentration distribution on the kinetics of drug release from glassy hydrogel matrices. Polymer, New York, v. 25, p. 973-978, 1984.
LEE, P. I. Kinetics of drug release from hydrogel matrices. $J$. Controlled Release, Amsterdam, v. 2, p. 277-288, 1985.

REINHART, C. T., KORSMEYER. R. W., PEPAS, N. A. Macromolecular network structure and its effect on drug and protein diffusion. Int. J. Pharm. Technol. Prod. Manuf., London, v. 2, p. 9-16, 1981.

SHAH, S. S., KULKARNI, M. G., MASHELKAR, R. A.pH dependent zero order released from glassy hydrogels: penetration vs. diffusion control. J. Controlled Release, Amsterdam, v. 15, p. 121-132, 1991.

SUJJA-AREEVATH, S.; MUNDAY, D. L.; COX, P. J., KHAN, K. A. Relations between swelling, erosion and drug release in hydrophilic natural gum mini-matrix formulations. Eur. J. Pharm. Sci., Amsterdam, v. 6, p. 207-217, 1998.

SYED, A.A.; KAREN YU; JAGDISH, P.; DAVID, R. F. Guar gum- based sustained release diltiazem. Pharm. Res., New York, v.15, n.8, p. 1196-1201, 1998.

TALUKDAR, M. M.; KINGET, R. Swelling and drug release behavior of xanthan gum matrix tablets. Int. $J$. Pharm., New York, v. 120, p. 63-72, 1995.

WADE, A.; WELLES, P.J., eds. Handbook of pharmaceutical excipients. Washington: American Pharmaceutical Association, 1994. p.84-87.

WU, CHENG-WE; LEE, JIN-GANG; LEE, WEN CHIEN Protein and enzyme immobilization on non-porous microspheres of polystyrene. Biotechnol. Applied Biochem., Colchester, v. 27, p 225-230, 1998.

Recebido para publicação em 25 de fevereiro de 2003. 